\title{
Magnetic nanoparticles preparation by chemical reduction for biomedical applications
}

\author{
Zhazgul Kelgenbaeva ${ }^{1,2^{*}}$, Bektemir Murzubraimov ${ }^{2}$, Artem Kozlovsky ${ }^{3}$, Ruslan Adil Akai \\ Tegin $^{4}$, Ainur Turdubai kyzy ${ }^{2}$, Elmira Murzabekova ${ }^{2}$, Janbolot Aidaraliev ${ }^{5}$, Begimzhan \\ Dyusheeva $^{1}$ \\ ${ }^{1}$ Department of Fundamental Disciplines, I. K. Akhunbaev Kyrgyz State Medical Academy, Bishkek, \\ Kyrgyzstan \\ ${ }^{2}$ Institute of Chemistry and Phytotechnology, National Academy of Sciences of the Kyrgyz Republic, \\ Bishkek, Kyrgyzstan \\ ${ }^{3}$ Institute of Nuclear Physics Astana branch, Astana, Kazakhstan \\ ${ }^{4}$ Department of Chemical Engineering, Kyrgyzstan-Turkey Manas University, Bishkek, Kyrgyzstan \\ ${ }^{5}$ Department of Physics and Applied Chemistry, N. Isanov Kyrgyz State University of Construction, \\ Transport and Architecture, Bishkek, Kyrgyzstan
}

\begin{abstract}
This work presents $\mathrm{Fe}_{3} \mathrm{O}_{4}$ and $\mathrm{AgFe}$ nanoparticles with an average diameter of 25 and $15 \mathrm{~nm}$ synthesized by chemical reduction of corresponding salts under a mild condition. Cubic crystal structure and spherical shape of the nanoparticles were studied by X-ray diffraction, Field emission SEM and energy-dispersive spectroscopy analysis. For biomedical applications, the nanoparticles were tested against bacteria E.coli and results revealed AgFe nanoparticles' antibacterial activity by forming lysis zone in scale of $0.5 \mathrm{~mm}$.
\end{abstract}

\section{Introduction}

Magnetic nanoparticles have been extensively studied in the past half century and continue to maintain interest because of their potential use in areas ranging from storage of high-density data to biomedical applications [1]. In particular, monodispersed magnetite $\left(\mathrm{Fe}_{3} \mathrm{O}_{4}\right)$ nanoparticles have given a new impetus in the application field where magnetic nanoparticles are extensively used in Ferro fluids, biological imaging and therapies [2, 3]. Magnetic bimetallic Fe-Ag nanoparticles exhibit significant antibacterial and antifungal activities against variety of microorganisms; also, they have numerous applications in optical, medical and remediation fields [4].

Physical and chemical methods are being used extensively for production of metal and metal oxide nanoparticles, such as co-precipitation of aqueous ferrous and ferric solutions [5], micro-emulsion technique [6] and hydrothermal synthesis [7]. Chemical reduction is one of the simplest, economically and ecologically friendly ways to prepare various monodisperse, small in size nanoparticles [8].

\footnotetext{
${ }^{*}$ Corresponding author: jaza-86@mail.ru
} 
The aim of this work is to prepare magnetic $\mathrm{Fe}_{3} \mathrm{O}_{4}$ and bimetallic $\mathrm{AgFe}$ nanoparticles for biomedical applications. The following objectives were set to achieve the goal: 1) synthesis of magnetite and $\mathrm{AgFe}$ nanoparticles by reduction of their corresponding salts under a mile conditions using hydrazine hydrate as a reducing agent; 2) to study the physicochemical properties and biological activities of synthesized nanoparticles.

We have synthesized magnetic magnetite (cubic $\mathrm{Fe}_{2.89} \mathrm{O}_{4.57}$ ) and bimetallic AgFe (cubic $\mathrm{Ag}_{0.4} \mathrm{Fe}_{0.6}$ phase) nanoparticles by reducing $\mathrm{FeSO}_{4} * 7 \mathrm{H}_{2} \mathrm{O}$ and mixture of two salts $\left(\mathrm{FeSO}_{4}\right.$ $* 7 \mathrm{H}_{2} \mathrm{O}$ and $0.05 \mathrm{M} \mathrm{AgNO}_{3}$ ) at room temperature using hydrazine hydrate as a reducing agent. Both, $\mathrm{Fe}_{3} \mathrm{O}_{4}$ and $\mathrm{AgFe}$ nanoparticles have spherical shape and size ranged between $15-30 \mathrm{~nm}$, based on SEM results. For biomedical applications, the nanoparticles' antibacterial activity was tested against E.coli bacteria; among the samples, bimetallic AgFe nanoparticles showed higher antibacterial activity.

\section{Experimental}

Two different samples were prepared in this study:

1. A mixture of 0.05 mole $\mathrm{FeSO}_{4} * 7 \mathrm{H}_{2} \mathrm{O}$ solution and surfactants (food gelatine and poly-vinyl-pyrrolidone (PVP)) in $50 \mathrm{~mL}$ beaker was placed on magnetic stirrer with temperature of $70-90{ }^{\circ} \mathrm{C}$ and rotation speed of 450-500 rpm. To achieve the alkaline $\mathrm{pH}$, concentrated $\mathrm{NaOH}$ was dropped into the solution ( $\mathrm{pH} \approx 11-12$ ). The $64 \%$ hydrazine hydrate $\left(\mathrm{N}_{2} \mathrm{H}_{4} * \mathrm{H}_{2} \mathrm{O}\right)$ solution served as a reducing agent and it was added into the mixture after the temperature reached $70{ }^{\circ} \mathrm{C}$. The reduction process continued for 30-35 minutes, until the solution turned into homogeneous dark colour, which was an indication of nanoparticles formation. After the experiment, the sample was separated from the liquid by centrifuge and dried at $60-70{ }^{\circ} \mathrm{C}$ in drying oven. Finally, powder-like dark sample was collected and labelled as Sample A. The following mechanism for formation of $\mathrm{Fe}_{3} \mathrm{O}_{4}$ nanoparticles can be drawn: Hydrazine hydrate acts as reducing agent and distilled water acts as supplier of oxygen. The role of sodium hydroxide is to supply basic $\mathrm{pH}$ for Fe ions reduction. Oxidation of $\mathrm{Fe}$ and formation of $\mathrm{Fe}$ oxides may occur due to exposure to air atmosphere, since the $\mathrm{Fe}$ is very active element or due to the interaction between $\mathrm{OH}^{-}$ions and $\mathrm{Fe}^{2+}$ during the synthesis. The general reaction can be written as:

$$
2 \mathrm{FeSO}_{4}+\mathrm{N}_{2} \mathrm{H}_{4} \text { (reducing agent) }+4 \mathrm{NaOH}=2 \mathrm{Fe}_{3} \mathrm{O}_{4}+\mathrm{N}_{2}+4 \mathrm{H}_{2} \mathrm{O}
$$

2. As for the Sample B, a mixture of two salts $\mathrm{FeSO}_{4} * 7 \mathrm{H}_{2} \mathrm{O}$ and $0.05 \mathrm{M} \mathrm{AgNO}_{3}$ was taken as an initial substance for production of bimetallic nanoparticles. Reaction processed at $80-90{ }^{\circ} \mathrm{C}$ for 30 minutes and hydrazine hydrate was served as reducing agent for both salts. After the reaction, the sample was separated from the liquid and dried.

Both Sample A and Sample B were then characterized. X-ray diffraction (XRD) measurement performed on a D-8 Advance ECO diffractometer with a $\mathrm{Cu}-\mathrm{K} \alpha$ radiation $(\lambda=0.15406 \mathrm{~nm})$ served to study crystal structure, phase composition and crystallite sizes of the samples. JEOL JSM-7500F Field-Emission Scanning Electron Microscope (FE-SEM) examined morphology and size and an Energy-Dispersive X-ray Spectroscopy (EDS) observed elemental composition analysis.

Antimicrobial activity of synthesized nanoparticles were conducted using E.coli (ATCC 35218) bacteria in Plate Count Agar (Merck-M105463) media by Hole method.

\section{Results and Discussion}

XRD pattern of Fe-system sample obtained by chemical reduction of $\mathrm{FeSO}_{4} * 7 \mathrm{H}_{2} \mathrm{O}$ using $\mathrm{N}_{2} \mathrm{H}_{4}$ as reducing agent presented in Figure 1 shows, that the sample is monophasic $\mathrm{Fe}_{3} \mathrm{O}_{4}$ with phase content of $100 \%$. The diffraction peaks are attributed to cubic $\mathrm{Fe}_{2.89} \mathrm{O}_{4.57}$ with space group of Fd-3m (227). Each identified peak location, hkl, distance between 
atomic layers (d) and size of each crystalite (L, nm) calculated by Sherrer formula [31, 32] were represented in Table 1 (Sample A). These results reveal that it was possible to prepare monophasic $\mathrm{Fe}_{3} \mathrm{O}_{4}$ with size ranged between 11-35 nm.

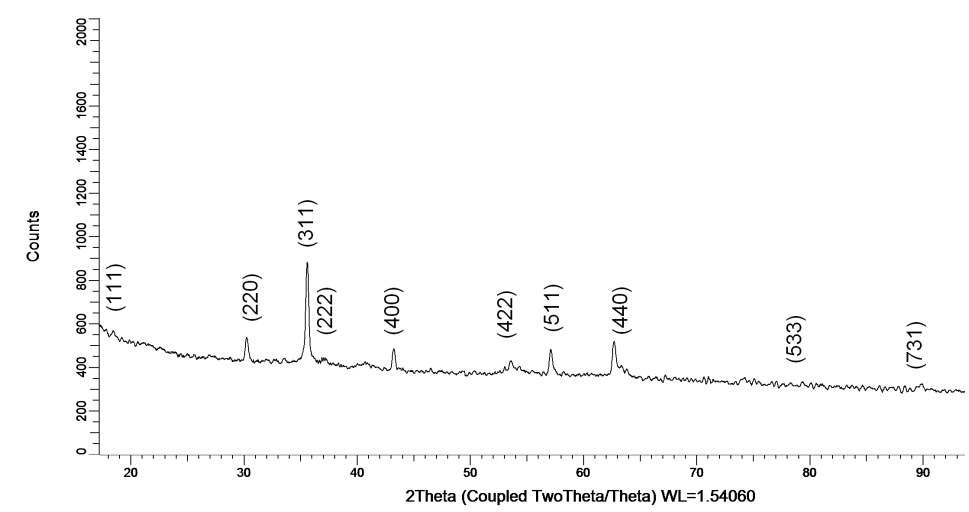

Fig. 1. X-Ray diffraction pattern of $\mathrm{Fe}_{3} \mathrm{O}_{4}$ nanoparticles by chemical reduction

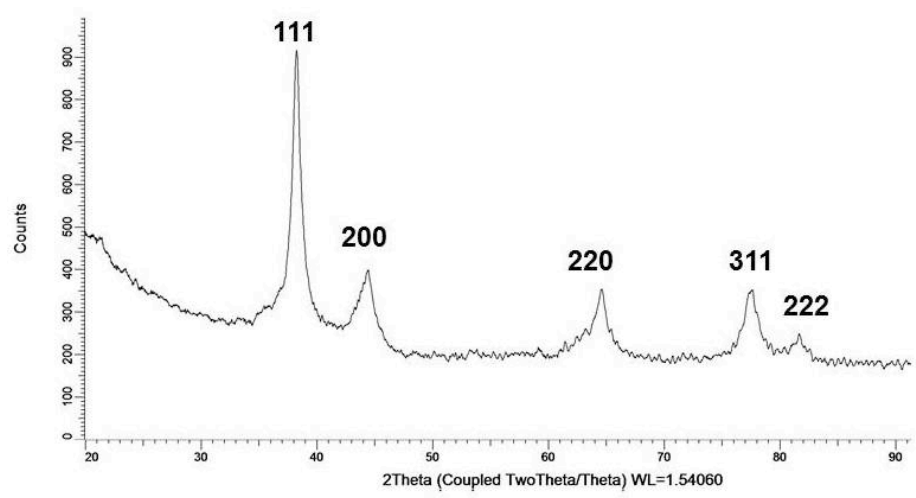

Fig. 2. X-Ray diffraction pattern of AgFe nanoparticles by chemical reduction

Figure 2 presents XRD pattern of Sample B, synthesized by chemical reduction of $\mathrm{FeSO}_{4}$ and $\mathrm{AgNO}_{3}$ under a mile condition with hydrazine hydrate. Diffraction peaks exhibit a cubic $\mathrm{Ag}_{0.4} \mathrm{Fe}_{0.6}$ phase with space group of $\mathrm{Fm}-3 \mathrm{~m}$, and was in good agreement with JCPDS no 03-8448. Phase content was $100 \%$ and crystalite size was found to be $7-26 \mathrm{~nm}$ from the X-ray line broadening (Table 1, Sample B).

Table 1. XRD data for $\mathrm{Fe}_{3} \mathrm{O}_{4}$ and $\mathrm{AgFe}$ nanoparticles synthesized by chemical reduction

\begin{tabular}{|l|l|l|l|l|l|l|}
\hline No & (hkl) & $\mathbf{2 0}^{\mathbf{0}}$ & $\mathbf{d}, \boldsymbol{\AA}$ & $\mathbf{L}, \mathbf{n m}$ & Lattice parameter, $\AA$ & FWHM \\
\hline \multicolumn{7}{|c|}{ Sample A } \\
\hline 1 & 111 & 18.439 & 4.80794 & 37.15 & \multirow{2}{*}{$\mathrm{a}=8.35946$} & 0.241 \\
\hline 2 & 220 & 30.044 & 2.97194 & 30.27 & & 0.302 \\
\hline 3 & 311 & 35.524 & 2.52501 & 29.60 & $(\mathrm{a}=8.34800-$ reference $)$ & 0.313 \\
\cline { 1 - 5 } 4 & 222 & 37.136 & 2.41904 & 34.41 & & 0.271 \\
\hline 5 & 400 & 43.261 & 2.08967 & 31.52 & & 0.301 \\
\hline 6 & 422 & 53.577 & 1.70911 & 11.36 & & 0.871 \\
\hline 7 & 511 & 57.231 & 1.60838 & 32.22 & & 0.312 \\
\hline
\end{tabular}




\begin{tabular}{|l|l|l|l|l|l|l|}
\hline 8 & 440 & 62.604 & 1.48264 & 28.85 & & 0.358 \\
\hline 9 & 533 & 73.994 & 1.28004 & 20.36 & & 0.544 \\
\hline 10 & 731 & 89.576 & 1.09342 & 17.80 & \\
\hline \multicolumn{7}{|c|}{ Sample B } \\
\hline 1 & 111 & 38.260 & 2.35528 & 11.45 & $\mathrm{a}=4.06020$ & 0.701 \\
\hline 2 & 200 & 44.206 & 2.04719 & 7.04 & & 1.355 \\
\hline 3 & 220 & 64.597 & 1.44090 & 9.19 & & 1.137 \\
\hline 4 & 311 & 77.557 & 1.23338 & 9.02 & & 1.255 \\
\hline 5 & 222 & 81.792 & 1.17660 & 26.19 & & 0.446 \\
\hline
\end{tabular}

Figure 3 (B and $\mathrm{C}$ ) shows that samples composed of element iron $(\mathrm{Fe})$, oxygen $(\mathrm{O})$ and silver (Ag). Figures 3A and 3D show spherical shape and small size of both $\mathrm{Fe}_{3} \mathrm{O}_{4}$ and $\mathrm{AgFe}$ nanoparticles. Due to their small size and intermolecular forces, nanoparticles gather together by forming spherical agglomerates.
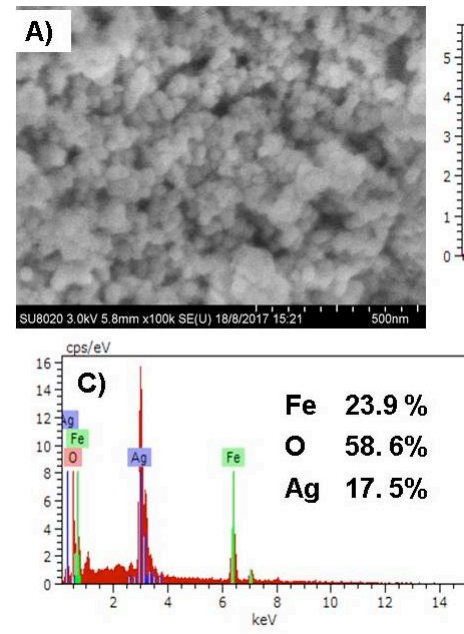
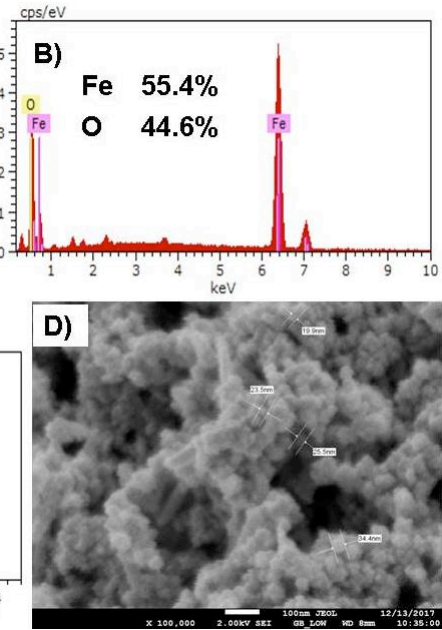

Fig. 3. Elemental composition and microphotography of $\mathrm{Fe}_{3} \mathrm{O}_{4}(\mathrm{~A}$ and $\mathrm{B})$ and $\mathrm{AgFe}(\mathrm{C}$ and $\mathrm{D})$ nanoparticles prepared by chemical reduction

Antibacterial activity of the nanoparticles prepared by chemical reduction method was determined for E.coli bacteria by hole method, which can be seen from the Figure 4: A, B and $\mathrm{C}$ for $\mathrm{Fe}_{3} \mathrm{O}_{4}, \mathrm{AgFe}$ and $\mathrm{Ag}$ nanoparticles, respectively. Samples were dropped to the holes and they had effect to bacteria cell growth. Pure Ag nanoparticles were taken for a comparison, since Ag is known for its anticeptic property in bulk, micro - and nano- scales. As shown from the image the $\mathrm{Fe}_{3} \mathrm{O}_{4}$ nanoparticles did not show any effect against bacteria; this can be explained by the addition of PVP and gelatine during the experiment, which could inhibit particles activity. Lysis zone for the AgFe nanoparticles was determined to be $0.5 \mathrm{~mm}$, while this value for pure Ag nanoparticles was 2-3 mm. The possible mechanism of action is that the metal nanoparticles are carrying the positive charges and the microbes are having the negative charges which create the electromagnetic attraction between the nanoparticles and the microbes. When the attraction is made, the microbes get oxidized and die instantly [9-10]. Generally, the nanomaterials release ions, which react with the thiol groups $(-\mathrm{SH})$ of the proteins present on the bacterial cell surface which leads to cell lysis [11].

Thus, based on these results one can conclude that noble metals like $\mathrm{Au}$ and $\mathrm{Ag}$ can increase bacterial activity of magnetic nanoparticles, i.e. coating of magnetic nanoparticles 
with noble metals opens new possibilities to expand an application field of nanoparticles in biomedicine.

\section{Conclusions}

Magnetic $\mathrm{Fe}_{3} \mathrm{O}_{4}$ and $\mathrm{AgFe}$ nanoparticles were synthesized by chemical reduction of $\mathrm{FeSO}_{4}$ and $\mathrm{AgNO}_{3}$ salts with hydrazine hydrate as reducing agent. The $\mathrm{AgFe}$ and $\mathrm{Ag}$ nanoparticles exhibited antibacterial activity against E.coli and the suppression zone size was 0.5 and 2-3 $\mathrm{mm}$, respectively. This work opens up new possibilities to prepare small in size and monodisperse biologically active nanoparticles for variety of applications.
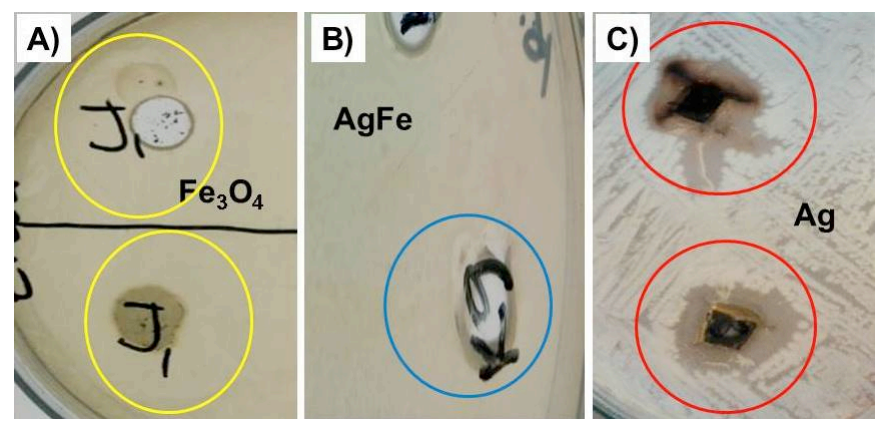

Fig. 4. Effect of antibacterial activity of $\mathrm{Fe}_{3} \mathrm{O}_{4}(\mathrm{~A}), \mathrm{AgFe}(\mathrm{B})$ and $\mathrm{Ag}(\mathrm{C})$ nanoparticles to the E.coli bacteria cell culture

This research was funded by the International Innovative center of Nanotechnology, CIS (Funding number: 038/110).

\section{References}

1. Z. Kelgenbaeva, E. Omurzak, S Takebe, S. Sulaimakulova, Z. Abdullaeva, C Iwamoto and T. Mashimo, J Nanopart Res., 16, 2603 (2014).

2. P. Oswald, O. Clement, C. Chambon, E. Schouman-Claeys and C. Frija. Magn Reson Imaging, 15, 1025 (1997).

3. D. Kim, Y. Zhang, J. Kehr, T. Klason, B. Bjelke and M. Muhammed, J Magn Magn Mater., 225, 256 (2001).

4. Z. Markova, K. Siskova, J. Filip, J. Cuda, M. Kolar, K. Safarova, I. Medrik and R. Zboril, Environ Sci Technol 21, 47 (2013).

5. Y. Kang, S. Risbud, J. Rabolt and P. Stroeve, Chem Mater, 8, 2209 (1996).

6. Z. Zhou, J. Wang, X. Liu and H. Chan, J. Mater Chem 11, 1704 (2001)

7. Z. Zhou, J. Wang, X. Liu, and H. Chan, J Phys Chem C, 113, 7181-85 (2009)

8. T.M. Dang, T. Le, E. Blanc and M. Dang,, Adv. Nat. Sci. Nanosci. Nanotechnol., 2, 15009-15012 (2011).

9. Y. T. Prabhu, K. Venkateswara Rao, B. Siva Kumari, V. S. Kumar and T. Pavani, Int. Nano Lett., 5, 85-92 (2015).

10. S. Rezaei-Zarchi, A. Javed, M. Ghani, S. Soufian, F. Firouzabadi, A. Moghaddam and S. Mirja lili, Iran J Pathol, 5, 83-89 (2010).

11. H. Zhang and G. Chen, Environ Sci Technol 43, 2905-10 (2009). 